\title{
Pressure welding of nickel-based 58Ni-Cr-Mo-B-Al-Cu alloy under low-temperature superplasticity conditions
}

\author{
E. V. Valitova ${ }^{\dagger}$, R. Ya. Lutfullin, M. Kh. Mukhametrakhimov, \\ V. A. Valitov, A. Kh. Akhunova, S. V. Dmitriev \\ †valitova_elvina_v@mail.ru
}

Institute for Metals Superplasticity Problems, RAS, 39 Khalturin St., 450001, Ufa, Russia

Both the ultrafine-grained (UFG) structure with a grain size $(d)$ less than $1 \mu \mathrm{m}$ and nanocrystalline (NC) structure $(d \leq \mathrm{nm})$ can be processed in nickel-based alloy $58 \mathrm{Ni}-\mathrm{Cr}-\mathrm{Mo}-\mathrm{B}-\mathrm{Al}-\mathrm{Cu}$ using methods severe plastic deformation, in particular, multistep isothermal forging within the temperature range of $\gamma+\delta-$ region on Bridgman anvils at strains $e=5,5$. Pressure welding performed under conditions of low temperature superplasticity $\left(T=800^{\circ} \mathrm{C}, \dot{\varepsilon}=10^{-4} \mathrm{~s}^{-1}\right)$ can provide solid state joining of the alloy under study being in different structure conditions as well as joining of samples with coarse-grained structure using a NC layer.

Keywords: nickel-based alloy, multistep isothermal forging, severe plastic deformation ultrafine-grained and nanocrystalline structure, low temperature superplasticity, pressure welding.

\section{Introduction}

Heat-resistant nickel-based alloy 58Ni-Cr-Mo-B-Al-Cu and his counterpart Inconel 718 is widely used for producing various components of rocket engines [1,2]. This alloy as well as other nickel-based alloyed alloys is a heterophase one and a result characterized by low workability in the initial coarse-grained condition. One of the most advance methods for increasing workability of nickel - based alloys is their transformation to a superplastic state. As known [2], this state can be obtained by processing UFG and NC structures in semi-products of these materials. At present processing of the specified structural states and studies of their physical and mechanical properties attracts much attention [3-7]. At the same time the extremely urgent task of modern material science is development of efficient methods for producing bulk semifinished products with UFG and NC structures out of hard to deform nickel that can be used in advanced deformation processing under conditions of low temperature superplasticity.

In this connection the goal of the present consideration is to study the influence of various methods of severe plastic deformation (SPD) on formation of UFG and NC structures in nickel based alloy $58 \mathrm{Ni}-\mathrm{Cr}-\mathrm{Mo}-\mathrm{B}-\mathrm{Al}-\mathrm{Cu}$, and evaluate the possibility to process a sound solid phase joint during pressure welding of samples in different microstructure states under conditions of low temperature superplasticity.

\section{Material and experimental procedure}

A hot worked rod, $80 \mathrm{~mm}$ in diameter, out of $58 \mathrm{Ni}-\mathrm{Cr}$ Mo-B-Al-Cu alloy was used for investigations. Its microstructure is completely recrystallized coarsegrained.

For processing forgings with UFG structure billets, $80 \mathrm{~mm}$ in diameter and $80 \mathrm{~mm}$ in height, were cut from the hot deformed rod. Multiple step isothermal forging of the billets specified was performed on a hydraulic 6.3 MN force press equipped with a die set. Multistep forging was conducted by the technique described in [2]. The deformation processing was performed within the temperature range $950-850^{\circ} \mathrm{C}$ with step by step decrease of the temperature by the technique described in $[8,9]$.

Mechanical tests of samples, $8 \mathrm{~mm}$ in diameter and $12 \mathrm{~mm}$ in height, were performed by the scheme of axial compression on an universal testing device "Schenck» at the temperature $800^{\circ} \mathrm{C}$, and the strain rate $10^{-4} \mathrm{~s}^{-1}$ by strains up to $25 \%$. The results of testing was used to plot a stress strain diagram A strain rate sensitivity coefficient «m» was determined using a technique of gradual strain rate decrease.

NC structure processing in a disk $10 \mathrm{~mm}$ in diameter and $1,27 \mathrm{~mm}$ in thick, was carried out by the method of SPD on Bridgman anvils by strains up to $e=5.5$ (a number of rotations $n=5$ ) under a pressure of 40 ton at room temperature, a rate of torsion being $2 \mathrm{rot} / \mathrm{min}$. Annealing of NC samples were performed in an electric furnace ATS at the temperature $800^{\circ} \mathrm{C}$ for 1 hour and cooling concurrently with the furnace.

Pressure welding was carried out on an IMASH $20-$ 78 type device. Samples with dimensions $5 \times 5 \times 0.27 \mathrm{~mm}$ and a NC interlayer with dimensions $5 \times 5 \times 0,27 \mathrm{~mm}$ were pressure jointed at the temperature $800^{\circ} \mathrm{C}$ and the initial strain rate $10^{-3} \mathrm{~s}^{-1}$ by strains up to $35 \%$. 


\section{Results and discussion}

Initial State. In the initial hot deformed state the alloy under study has a coarse-grained (CG) structure with an average grain size ( $\gamma$-phase) of about $62 \mathrm{~mm}$ and strengthening $\gamma^{\prime \prime}$ phase precipitates of a nanoscale size (Fig.1).

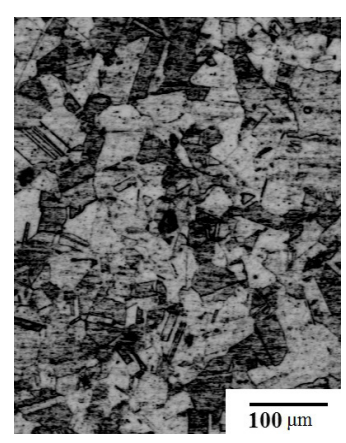

a

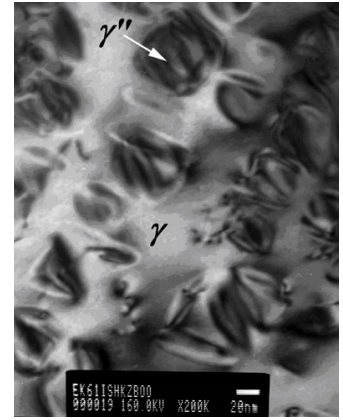

$\mathrm{b}$
Fig. 1. Initial state of alloy HN58MBUD: (a) Optical metallograhy; (b) TEM.

Microstructure after IMF. During heating up to the temperature of IMF the metastable $\gamma^{\prime \prime}$ - phase is completely dissolved and then in the process of strain-heat treatment within the identified temperature range the precipitation of heat stable $\delta$-phase occurs. Due to SPD realized by means of IMF a homogeneous UFG duplex type microstructure is formed within the whole material interior. The processed UFG structure is characterized by the presence of fine eqiaxial grains of $\gamma$ - phase which are predominantly free of dislocations. The grain boundaries are distinct and most of them have specific banded contrast typical of equilibrium high angle grain boundaries. At the same time a high density

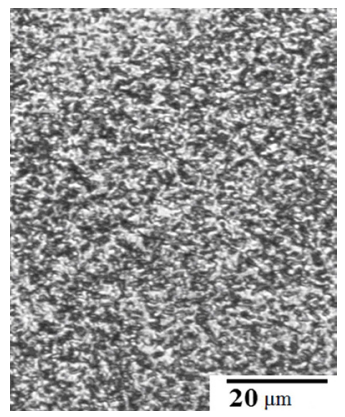

a

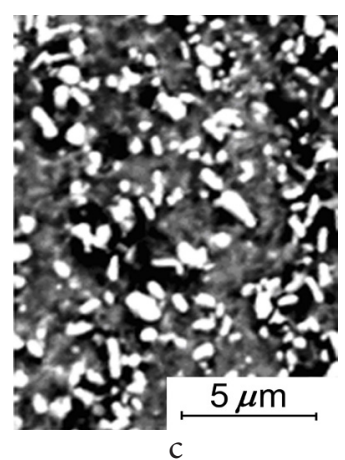

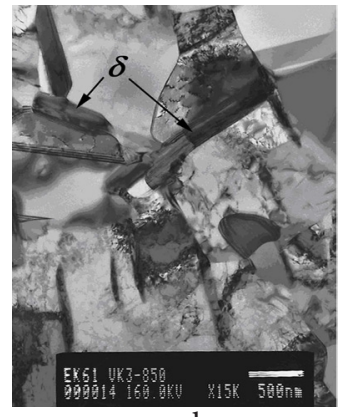

b

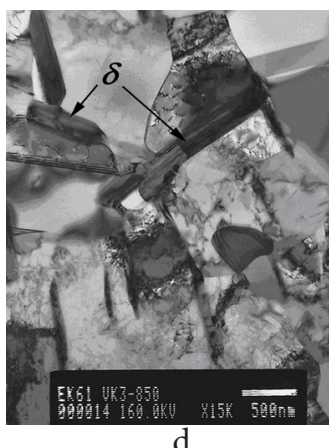

Fig. 2. Microstructure of the alloy after MIF within (a, b) the temperature range $950-850^{\circ} \mathrm{C}$ and following deformation (c, d) at temperature $800^{\circ} \mathrm{C}$. of dislocations is revealed within the interior of some grain boundaries (fragments) (Fig.2a,b). Non-coherent $\delta$-phase particles are present at grains and triple junctions of $\gamma$-phase grains most particles are of an ellipsoid form (Fig.2b) though some of them have a more circular globular form. The volume fraction of $\delta$-phase is about $27 \pm 2 \%$.

Thus, the homogeneous UFG microstructure of a microduplex type has been formed within the whole deformed material interior (Fig.2a). The processed microstructure consists of $\gamma$-phase grains less than $1 \mu \mathrm{m} \mathrm{m}$ in size and noncoherent $\delta$-phase precipitates (Fig. $2 \mathrm{~b}$ ).

The superplastic properties of UFG alloy have been studied by uniaxial tensile testing within the temperature range $600-1000^{\circ} \mathrm{C}$. The peak of superplasticity is observed at the temperature $800^{\circ} \mathrm{C}$. The investigations dealing with the possibility of solid phase joining in alloy $58 \mathrm{Ni}-\mathrm{Cr}-\mathrm{Mo}-$ $\mathrm{B}-\mathrm{Al}-\mathrm{Cu}$ has been performed at $800^{\circ} \mathrm{C}$ at which maximum manifestation of low temperature superplasticity is observed. (Fig.3).

Microstructure transformation in UFG alloy $58 \mathrm{Ni}-\mathrm{Cr}$ $\mathrm{Mo}-\mathrm{B}$ - $\mathrm{Al}-\mathrm{Cu}$ during isothermal deformation by the scheme of uniaxial compression. The microstructure of the UFG alloy after deformation by strains up to $\varepsilon=25 \%$ at the initial strain rate $\dot{\varepsilon}=10^{-4} \mathrm{~s}^{-1}$ and the temperature $800^{\circ} \mathrm{C}$ is shown in Fig.2b,c. Deformation at $800^{\circ} \mathrm{C}$ does not actually results in essential changes in the UFG structure processed from IMF. Note that after deformation in the regime of low temperature superplasticity the UFG structure of the alloy under study is characterized by the presence of only stable non-coherent precipitates of heat stable $\delta$-phase similar to IMF. Unlike the microstructure after IMF the $\delta$-phase particles are of a more circular form. That is evidently attributed to the action of mechanisms of superplastic deformation, in particular, the occurrence of grain boundary sliding which intense the processes of coagulation and spheriodization of second phase precipitates (Fig.2d). Moreover, the banded contrast is revealed at a number of $\gamma / \delta$ interphase boundaries which testifies to high angle misorientation of such grains. The volume fraction of $\delta$-phase particle is $25 \pm 3 \%$.

Microstructure after SPF on the Bridgman anvils. After SPD on Bridgman anvils at the strains e-5.5. a structure typical of NC materials with a mean fragment size of about $100 \mathrm{~nm}$ is formed. (Fig.4a).

Mirostructure of NC material after annealing. The microstructure of the alloy is homogeneous. The $\delta$-phase



Fig. 3. Low-temperature superplasticity of UFG 58Ni-Cr-Mo-BAl-Cu alloy. 




a

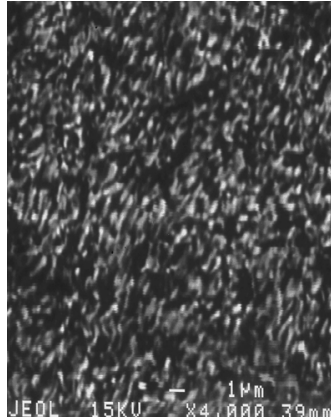

$\mathrm{b}$



C

Fig. 4. Microstructure of samples after SPD on (a) Bridgman anvils and following annealing for 1 hour (b, c) at temperature $800^{\circ} \mathrm{C}$.

particles are distributed uniformly within the whole interior. (Fig.4b) One can see that grains (fragments) are elongated in the direction of material flow that correlates the data given in [6]. The volume fraction of the second phase is $28+3 \%$. A number of annealing twins are observed in the structure (Fig.4c). One should note that the structure of the NC alloy after annealing is not homogeneous and consists of misorientated crystals of various sizes: relatively coarse, about $1.2 \mu \mathrm{m}$ in sized, and fine, about $100 \mathrm{~nm}$ in size.

Microstructure of solid phase joint (SPJ) processed from pressure welding at the temperature $800^{\circ} \mathrm{C}$. The results of experiments on pressure welding of two coarse-grained samples out of $58 \mathrm{Ni}-\mathrm{Cr}-\mathrm{Mo}-\mathrm{B}-\mathrm{Al}-\mathrm{Cu}$ alloy (Fig.5a) have shown that SPJ can be processed at the temperature $800^{\circ} \mathrm{C}$. It is evidently attributed to the fact that the alloy $58 \mathrm{Ni}-\mathrm{Cr}$ Mo-B-Al-Cu with coarse-grained structure does not display superplastic properties. The deformation of samples is minimum and about $5 \%$. That is why the possibility of processing SPJ in different combinations of structure states has considered. In the combination UFG+UFG the both samples have been deformed similarly (Fig.5b). The total strain is about $35 \%$. The data of metallographic analysis have shown the relative length of pore in the joint is less than 10\% (Fig.5c). There are areas where the surface of the joint is normal to the axis of the load applied.

The investigation of SPJ in the combination CG+UFG has revealed that the UFG sample is deformed mainly. The total strain is $29 \%$ while the strain of the UFG sample is $45 \%$ (Fig.6a). There are elongated areas which orientation is normal to the axis of the load applied. And these areas are located in the center portion of the samples joint. A relative length of pores in these areas is about $80 \%$ (Fig.6b). Note that on the areas of SPJ being inclined to the axis o the load applied a sounder joint has been processed, a low relative length of pores being up to $10 \%$ testifies that (Fig.6c). One can assume that localization of plastic deformation evidently takes places therein.

The most interesting results have been obtained at pressure welding of samples via a NC layer (Fig.7). It has been revealed that the NC interlayer has been deformed preferably. In spite to the fact that the total strains is only $16 \%$ the strains of the NC interlayer is distributed non-uniformly and its value increases from the center to the surface of edge portions where it achieves $50 \%$. In the vicinity of the edge portion a relative length of pores is low (less than 10\%) (Fig.7). Note that even in the center portion (Fig.7) where deformation of the NC interlayer is minimum a relative length of pores is observed (less than 10\%). The strength of such joint is half the strength of the initial coarse grained material.

\section{Summary}

1. It has been shown experimentally that the SPD-method realized on the Bridgman anvils provides processing fragmented NC structure with a fragment size less than 100 $\mathrm{nm}$ in the alloy $58 \mathrm{Ni}-\mathrm{Cr}-\mathrm{Mo}-\mathrm{B}-\mathrm{Al}-\mathrm{Cu}$. After annealing at the temperature $800^{\circ} \mathrm{C}$ for 1 hour the NC structure transforms to a more equilibrium UFG structure consisting of $\gamma$-phase grains from 0,1 to $1,2 \mu \mathrm{m}$ in size.

2. The homogeneous UFG structure of a duplex type has been formed in the $58 \mathrm{Ni}-\mathrm{Cr}-\mathrm{Mo}-\mathrm{B}-\mathrm{Al}-\mathrm{Cu}$ alloy within the whole interior of the material by means of the method of multistep forging. After deformation at $800^{\circ} \mathrm{C}$ by the strains

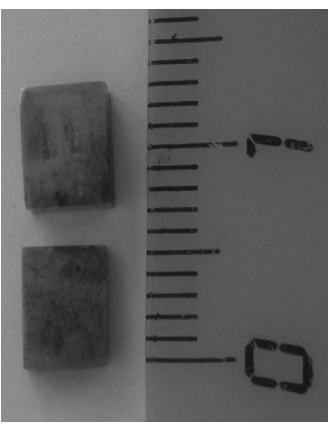

a

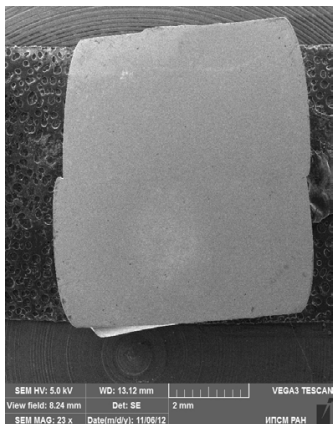

$\mathrm{b}$

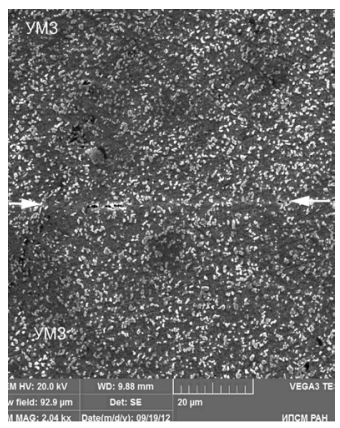

C

Fig. 5. Pressure welding of samples CG+CG (a) and UFG+UFG (b, c) out of alloy 58Ni-Cr-Mo-B-Al-Cu at temperature $800^{\circ} \mathrm{C}$. 


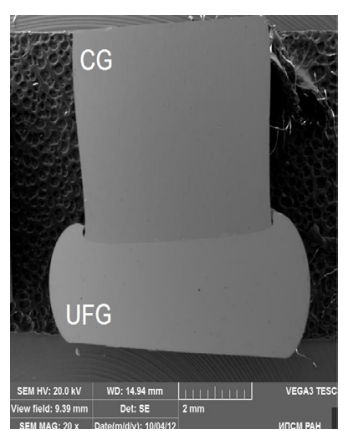

a

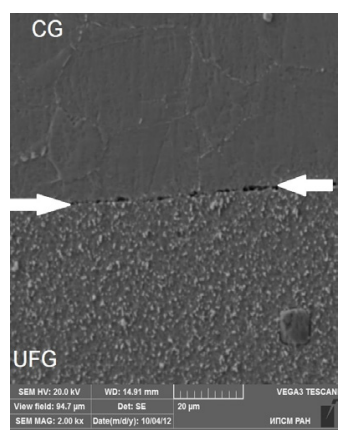

b

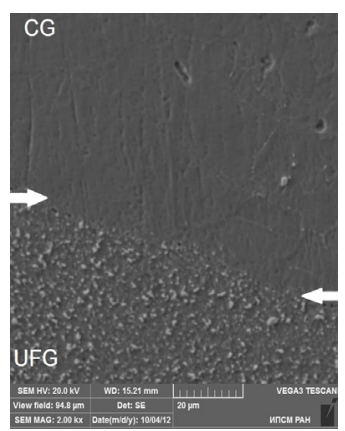

C

Fig. 6. SPJ of samples CG+UFO of alloy $58 \mathrm{Ni}-\mathrm{Cr}-\mathrm{Mo}-\mathrm{B}-\mathrm{Al}-\mathrm{Cu}$ after pressure welding at temperature $800^{\circ} \mathrm{C}$ : (a) general view and (b, c) local portions.

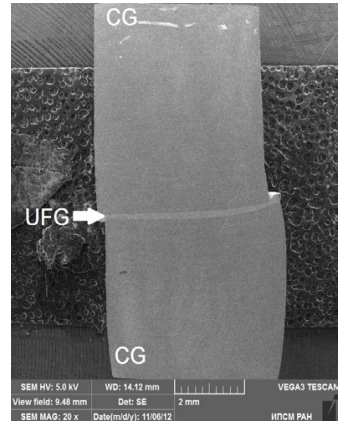

a

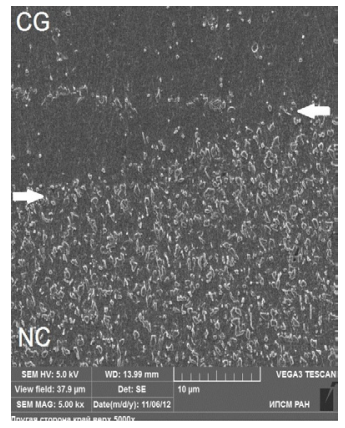

b

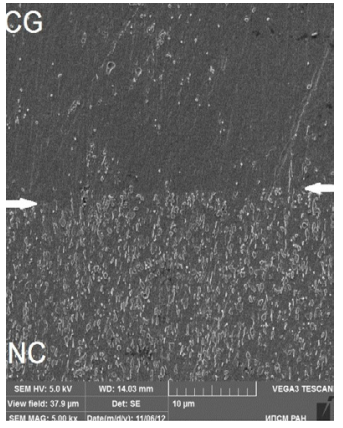

C

Fig. 7. SPF of samples CG+NC+CG of alloy $58 \mathrm{Ni}-\mathrm{Cr}-\mathrm{Mo}-\mathrm{B}-\mathrm{Al}-\mathrm{Cu}$ after pressure welding at temperature $800^{\circ} \mathrm{C}$ : (a) general view and (b, c) local portions.

up to $25 \%$ the UFG structure with a $\gamma$-phase grain size less than $1 \mathrm{~mm}$ is preserved. The volume fraction of the noncoherent $\delta$ phase is about $25 \pm 3 \%$.

3. The application of UFG and NC layers provides successfully processing solid phase joining of coarse-grained samples out of nickel-based alloys under conditions of low temperature superplasticity.

This work was performed with the financial support of the grant RFBR № 13-08-12200\14 and regional 14-08-97061.

\section{References}

1. B. M. Gromko. Metallovedenie i termicheskaya obrabotka. 6, 14 (2003). (in Russian)

2. C. T. Sims, N. S. Stoloff, W. C. Hagel. Transl. from Eng. In books. Superalloys II. Book 1 M., Metallurgiya. (1995) 384 p. (in Russian)

3. O.A. Kaibyshev, F.Z. Utyshev. Superplasticity: Microstructurial Refinement and Superplastic Roll
Forming, Futurepast, Arlington, VA22201 USA (2005) $386 \mathrm{p}$.

4. V.A. Valitov, R.R. Mulyukov, M.F. X. Gigliotti, P.R. Subramanian. Proc. of the Conference «Superalloys 2008». In Book «Superalloys 2008». TMS. (2008) p. 325.

5. O.R. Valiakhmetov, R.M. Galeyev, R.M. Imayev, A.A. Kruglov, R. Ya. Lutfullin, R.R. Mulyukov, A.A. Nazarov, R.V. Safiullin, V.A. Ivanko, A.A. Inozemtsev, N.L. Koksharov, S.A. Kharin. Nanotechnologies, 5(1-2), 108 (2010). (in Russian)

6. R.Z. Valiev, A.P. Zhilyaev, T.G. Langdon Bulk Nanostructured Materials: Fundamentals and Appllications. TMS, Wiley. (2014) 440 p.

7. I. A. Ditenberg, S. A. Malakhova, A.N. Nyumenzshev, A. V. Korznikov. Perspektivnye materialy. 12, 306 (2011). (in Russian)

8. V.A. Valitov. Voprosy materialovedeniya. 52(4), 311 (2007). (in Russian)

9. V.A. Valitov. Letters of materials. 3(1), 50 (2013). (in Russian) 